\title{
The Research on the Mode and Advantages of Applying Cloud Computing in China's SMEs Accounting Information
}

\author{
Dong-Dong Weng ${ }^{1, a}$, Xiao-Fang Wang ${ }^{2, b}$, Yao-Xiang Bi ${ }^{3, c}$ \\ ${ }^{1,3}$ Quanzhou Normal University, Fujian, Quanzhou, China \\ ${ }^{2}$ Liming Vocational University, Fujian, Quanzhou, China \\ a'weng28911985@163.com, bwxf@Imu.cn, c2602108793@qq.com
}

Keywords: Cloud computing, Application pattern, Big data era.

\begin{abstract}
Cloud computing, as a emerging calculation mode and service pattern, brings infinite reverie for developing Accounting Information. This paper, in a setting of big data era ,analyzes the present development status of China's SMEs accounting information, indicates many issues that may be encountered during the development process, and points out the advantages of applying cloud computing mode in China's SMEs accounting information.
\end{abstract}

\section{Present Status of China's SMEs Accounting Information}

\section{Social Environment Limits SMEs Accounting Information Technology Development}

SMEs accounting information technology development is inseparable from the social environment, relying on the whole social environment basis as support and protection.

\section{Internal Problems of the SMEs Accounting Information Technology Development}

Compared with large state-owned enterprises, there are multiple issues such as a shortage of enterprise funds, quality of personnel, lack of technical personnel, low computer application level ,etc, which make SMEs lack in internal understanding about accounting information, SMEs' employees get wrong the concrete of accounting information, in terms of ideology ,they have a superficial understanding towards the fact that the enterprise information technology will help promote the development of enterprises, enhance the competitiveness of enterprises .

\section{Flaws of China's SMEs Accounting Information Model}

The accounting information development has two main modes. First, the outsourcing of financial information software, taking into account the applicability and effect on the market, SMEs tend to buy the relevant financial modules from well-known software vendors, these large software vendor's software is practical and popular, it is worth sure, this approach can meet the SME sat a low cost to buy standardized financial module and achieve low levels of accounting information. However, the mass of standardized financial module cannot absolutely meet their own development needs of different enterprises in different sectors, which lack the characteristics of their business structure for SMEs, in this mode, with the continuous development of enterprises, it will be complex and difficult to expand accounting information from accounting field to the overall enterprises planning and implementation. Which to some extent is not conducive to SMEs accounting information development itself. Second, SME sout source their financial accounting to the respective professional bodies to complete, in which way they can solve the shortage of SMEs accounting personnel issues. However it's conducive for SMEs themselves to focus on production and management, while also reducing its its capital expenditures, but in this model, not only may financial and accounting information leak but also accounting information may not convey and feedback on time, which prevents SMEs from developing. Thus, SMEs development model of accounting information is still not perfect. 


\section{Outlines of Cloud Computing}

\section{The Concept of Cloud Computing}

The power of technology often show works by the science and technology, in terms of cloud computing, its basic working principle is: large amounts of data and processor resources integrated to enable distributed computing on a large number of distributed computers, rather than the local computer or a remote server In that run the data center similar to the Internet. The image of that, theoperation mode of cloud computing is similar to that of water and electricity required by public family life, in this mode, resources intensively collected, supply unitedly supplied, demand in demands, not only inexpensive, but also convenient.

\section{The Basic Characteristics of Cloud Computing}

Compared with the traditional computing service model, cloud computing and service model admittedly has its own advantages and essential characteristics as an emerging computing model .To combine multiparty ideas and indicate things based on research, the paper argue that cloud computing reflects the basic characteristics in the society development as the following aspects:

Powerful calculating capability; flexible service mechanisms ; The highly virtual and independent technology; Reasonable investment

\section{Cloud Computing Information Technology in the SMES Accounting Application Mode}

\section{SaaS Application Model}

SaaS (Software as a Service) translated into software as a service. Which means SMEs no longer need to purchase the software, but customize and hire the appropriate accounting software modules from cloud services providers according to their own actual business demands, cloud bears all advanced operating costs and post-management and service fees. Users no longer need to consider any of the software installation, upgrades, maintenance and other issues, but calculate payments to cloud service providers according to their own software and services ordered by kind, time and other factors. Thus, cloud services providers and SMEs carry out their duties, mutual service, which also brought convenience and development for both accounting information software service providers and SMEs.

\section{PaaS application model}

PaaS (Platform as a Service) translated as platform as a service. Which means cloud services providers rent network applications to SMEs, which is a further extension of the SaaS model. Accounting information of SMEs requires deepening as the enterprises develop, and it's an important way to use the service platform or environment offered by cloud providers to carry out accounting information, which is a revolution of finance management software, in which way, not only can enterprises accelerate applying their business processes and ideas to software, but also SaaS can continue to expand, so that enterprises achieve their accounting information deepening and greatly improve the efficiency .

\section{IaaS Application Mode}

IaaS (Infrastructure as a Service) translated as infrastructure as a service. Which means cloud services providers supply customers with the cloud infrastructure that are made up of servers ,computer networking, storage, data center and other infrastructure components, and users only need to pay an application fee based on the actual usage of the device. In short, IaaS model is a kind of service model that cloud service providers hosting the related hardware rental. Thus, cloud services providers have ownership of infrastructure, which are responsible for the daily operation and maintenance of infrastructure, while the user has the right to use, who requires a fee for their own use. In the past, the construction of accounting information in enterprises often requires a lot of capital in the construction and maintenance of infrastructure, high cost accounting information in order to build the appropriate accounting information environment. While in the IaaS application 
mode, SMEs no longer need to purchase infrastructure or spend a lot of money, just simply rent their own infrastructure according to their needs, which greatly reduces the cost of enterprise hardware resources, making more use of funds for SMEs to optimize.

\section{The Advantages of Applying Cloud Computing in the SMES Accounting Information Development in China}

\section{Cloud Computing Model Will Help Improve the Application of Information Technology for SMES accounting efficiency}

The quality requirements of accounting information in one of eight is to ensure the timeliness of accounting information, which is often difficult to achieve for accounting information processing legacy mode. The cloud-based accounting information system is based on the Internet model, cloud computing with its powerful computing capability and flexible service companies can make all the accounting information processing requirements be accessed through the network in a timely cloud computing services platform, which means that users will be able to connect to the network, it is possible anywhere at any time to obtain the services they need. By the cloud computing model, accounting staff of enterprises can rely on the Internet to handle accounting information, accounting, work out accounts, reimbursement and other work can be carried anywhere, realizing the true sense of the timeliness of accounting information processing, while corporate executives can also view real-time financial data of enterprises, and promptly make the appropriate management or decision-making, to achieve timely transmission of information and good decision management. In addition, in terms of cross-regional business for SMEs, cloud computing model let the accounting staff in different parts work together across time and space to achieve the work, no doubt, which greatly improves the SME accounting application of information technology efficiency .

\section{The Cloud Computing Model Can Meet the Needs of Smes Accounting Information and Flexible Business}

SMEs often adjust their business direction in order to facilitate competition and adapt to the market, it also illustrates the accounting information construction for SMEs need flexible scalability, the accounting information systems need to scale with your business or business development and flexible changes. And China has a large number of SMEs, of which industries range widely, under the traditional model of accounting information software sold most common and the lack of SME's own personality on the market, which makes accounting information rigid and lack of scalability. The cloud computing model, PaaS application mode is a good solution to this problem, it provides online development platform to meet the SME development model in accordance with their respective software tailored to the needs, thus ensuring that the SME accounting information may expand, adapt needs of the competitive environment in the market and flexible business.

\section{The Cloud Computing Model Can Reduce the Cost of Investment in Information Technology Accounting for Smes}

In addition, there should be running late hardware upgrades, maintenance and other capital investment, giving much pressure to the overall SME investment, which will also cause accounting information management many problems. Under the cloud computing application model, cloud service providers and SMEs carry out their duties, achieve division of work and common development. It is responsible for cloud service providers to build the operation of the network infrastructure and software and hardware platform required by accounting information, so that SMEs do not need to worry about the implementation and operation and maintenance of the late .In addition, it will not only provide more professional accounting information management consulting for SMEs, but also SMEs can receive timely application of the latest technology, small and medium enterprises will neither need to spend big money to buy the hardware and software infrastructure, nor to waste more human resources, not to mention that worrying about backward management accounting information. In their relationship, users only need to pay for services on demand to 
obtain their own accounting information system. Thus, cloud-based accounting information, enabling SMEs to reduce the cost accounting information input, ensuring the accounting information needs of its evolving.

\section{The Cloud Computing Model Will Help Improve the Safety and Reliability of the Accounting Information}

Safety and reliability of accounting information is very important for SMEs to do decision-making, in the past, most SMEs accounting information stored in the hardware system, when it is destroyed or suffered other hardware systems, it causes serious impact on force majeure enterprises, the traditional model SMEs can hardly completely overcome this, due to lower capacity or financial problems. Under the cloud computing model, SMEs accounting data sent over the network to the cloud anytime, anywhere, at the same time, distributed storage approach of cloud computing will make the accounting data multiple backups and save it in multiple areas, these data will not only be managed by a professional team, but also be protected by professional security management facilities, so the cloud computing model improves the safety and reliability of SMEs accounting information data.

\section{References}

[1] Victor Mayr Schonberg Big Data Era: big change of life, work and thought [M] Zhejiang People's Publishing House, 2012.

[2] Cheng Ping, He Xuefeng "Cloud Accounting" application [J] in the SME accounting information of Chongqing University of Technology (Social Science), 2011,25 (1): 55-60.

[3] Wangwen Lian Accounting Information and Its Effect [J] Shanghai Lixin University of Commerce, 2007,6 (21): 21-24.

[4] Dinglu investigate cloud-based SME financial accounting information [J] accounting communications, 2011 (3): 124-125.

[5] Liu Shuang, Xie Wu cloud computing in the enterprise accounting information in the application [J] accounting information, 2012 (5): 62-64.

[6] Tan Murong current development of the accounting information for SMEs and thinking [J] New Economy, 2012 (2): 159-160.

[7] Wang Jian, Yang Zhendong explore cloud-based SME financial information application mode [J] Chinese management information, 2009,12 (17): 53-54. 